\title{
Assessment of Papillary Fibroelastoma of the Semilunar Valves by Three-Dimensional Echocardiography
}

\author{
Leonel Avendaño-Pérez ${ }^{1}$, Nydia Ávila-Vanzzini² ${ }^{2}$ Nilda Espinola-Zavaleta ${ }^{{ }^{*}}$ \\ ${ }^{1}$ Laboratory of Non-Invasive Hemodynamics, National Institute of Cardiology “Ignacio Chávez", Tlalpan, Mexico \\ ${ }^{2}$ Department of Out-Patients Clinic, National Institute of Cardiology “Ignacio Chávez”, Tlalpan, Mexico \\ Email: *niesza2001@hotmail.com
}

How to cite this paper: Avendaño-Pérez, L., Ávila-Vanzzini, N. and Espinola-Zavaleta, N. (2017) Assessment of Papillary Fibroelastoma of the Semilunar Valves by ThreeDimensional Echocardiography. World Journal of Cardiovascular Diseases, 7, 429-434. https://doi.org/10.4236/wjcd.2017.712041

Received: October 31, 2017

Accepted: December 9, 2017

Published: December 12, 2017

Copyright $\odot 2017$ by authors and Scientific Research Publishing Inc. This work is licensed under the Creative Commons Attribution International License (CC BY 4.0).

http://creativecommons.org/licenses/by/4.0/

\begin{abstract}
Papillary fibroelastoma is an uncommon tumor. Recognitions of this tumor have been improved thanks to modern imaging advances, which have made more patients to be identified, but at the same time, the management of this disease is still controversial. There aren't enough studies to basic clinical actions. We present 2 interesting cases involving the semilunar valves. The purpose of presenting these cases is to review this rare disease and the superiority of the three-dimensional echocardiography in their diagnosis.
\end{abstract}

\section{Keywords}

Heart Tumor, Papillary Fibroelastoma, Pulmonary Valve, Aortic Valve, Echocardiography

\section{Background}

The valvular papillary fibroelastoma is an uncommon primary cardiac tumor, ranging from $0.002 \%$ to $0.02 \%$ in prevalence, [1] [2]. Papillary fibroelastoma is the third most common primary cardiac tumor (after myxoma and lipoma), accounting for $7 \%$ to $9 \%$ of benign primary tumors. Previous studies have shown that papillary fibroelastoma has predilection for left heart valves (ninety-five percent of these tumors arise from; aortic valve- $44.5 \%$ more than mitral valve-36.4\%). Papillary fibroelastoma that affects the right heart is unusual and when it is seen, the pulmonary valve is affected less often than the tricuspid valve and accounts for $8 \%$ of cardiac papillary fibroelastomas [1]. The incidence of papillary fibroelastoma of the pulmonary valve is reported in Klarich KW et al. in 1997 to be between $0.00017 \%$ and $0.033 \%$ at autopsy and $0.019 \%$ in clinical 
series [3]. Patients older than 40 years of age are primary among those who are diagnosed with papillary fibroelastoma; however, this tumor has also been described in neonates with congenital cardiac abnormalities [4] [5]. Anderson KR et al. reported that trisomy E neonate had congenital cardiac anomalies, which include ventricular septal defect, bicuspid aortic valve, and a congenital papillary tumor of the tricuspid valve-a unique case in the literature that reported an association between papillary fibroelastoma and congenital heart disease [6].

The histogenesis of papillary fibroelastoma is still unclear; there are several theories about its origin. Some authors consider these tumors to be neoplasms or hamartomas, whereas others believe them to be endocardial responses to infection or hemodynamic trauma [4].

Recognitions of these fibroelastomas have been improved thanks to new techniques and multimodality imaging studies which have made more patients to be identified, and have shown us how to manage these kinds of cardiac tumors.

The lack of information is still controversial, because there aren't enough studies to basic clinical actions. These are often incidentally detected by cardiac imaging. Surgical resection is curative and should be considered for symptomatic patients and those with large $(>1 \mathrm{~cm})$ and or mobile tumors. All other patients should be periodically followed with transthoracic echocardiography [3] [7].

The main aim of this study is to describe two cases of fibroelastomass in the semilunar valves, and to demonstrate the superiority of three-dimensional transesophageal echocardiography in their diagnosis.

\section{Cases Presentation}

\subsection{Papillary Fibroelastoma of Pulmonary Valve}

A 61-year-old man with history of heart murmur in childhood and family history of systemic arterial hypertension and dyslipidemia. He was asymptomatic without follow-up until the 35 years old, when he came to our institution with dyspnea of great efforts.

In 2015 he developed systemic arterial hypertension and ischemic heart disease. The laboratory test showed hyperlipidemia with total cholesterol was 245 mg/dl, HDL $38 \mathrm{mg} / \mathrm{dl}$ and LDL $137 \mathrm{mg} / \mathrm{dl}$, Table 1.

He was sent for transthoracic echocardiography, which identify dilatation of the right cavities, moderate pulmonary hypertension with systolic pulmonary

Table 1. Sociodemographic and clinical characteristics of the patients.

\begin{tabular}{ccc}
\hline & Patient 1 & Patient 2 \\
\hline Age (years) & 61 & 68 \\
Sex & Man & Woman \\
BMI $\left(\mathrm{Kg} / \mathrm{m}^{2}\right)$ & 32.5 & 29 \\
Cardiovascular risk factors & Systemic arterial hypertension & Dyspilidemia \\
Clinical characteristics & Dyslipidemia & Asymptomatic
\end{tabular}



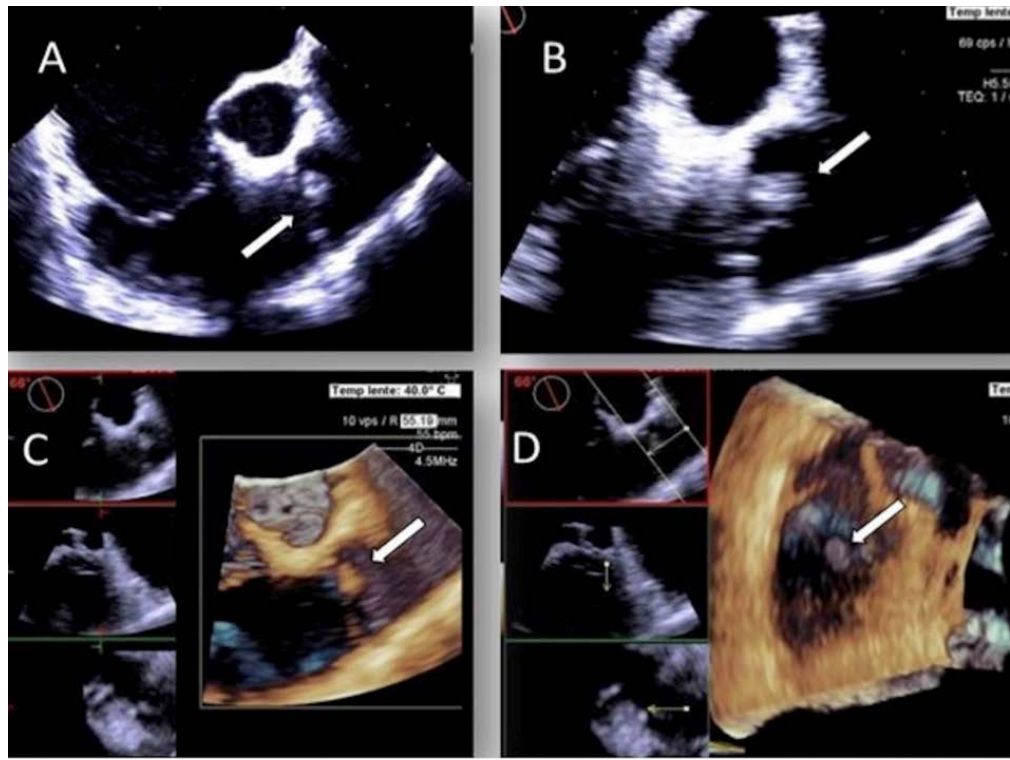

Figure 1. Transesophageal study. (A) Bidimensional mid-esophageal image at $70^{\circ}$, showing the mass at the level of pulmonary valve (white arrow); (B) Bidimensional midesophageal image in zoom, showing the mass attached to the pulmonary valve (white arrow); (C) Real-time three-dimensional mid-esophageal image at $70^{\circ}$ showing the pulmonary mass (white arrow); (D) Real-time three-dimensional mid-esophageal image, showing the pulmonary mass (white arrow) in short axis of the pulmonary valve in order to visualize the pulmonary mass.

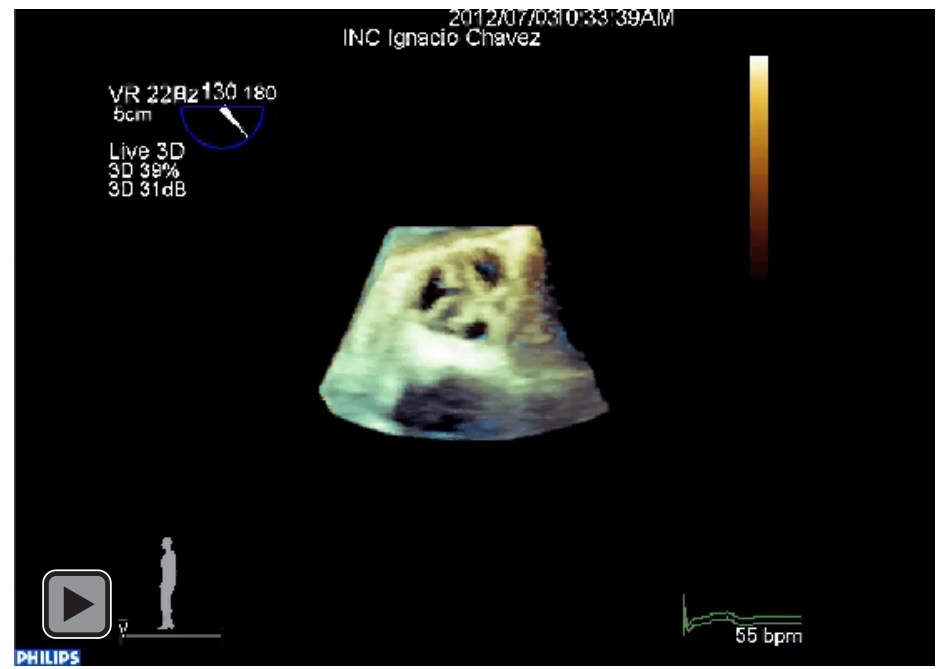

Video 1. Real-time three-dimensional mid-esophageal image, showing the pumonary mass.

artery pressure of $63 \mathrm{mmHg}$ and an ostium secundum atrial septal defect and the two and three-dimensional transesophageal echocardiography revealed a $12 \mathrm{~mm}$ hyper-echogenic mass attached on the pulmonary valve, without any interference of the valvular function (Figures $1(\mathrm{~A})$-(D) and Video 1 ) not described in the transthoracic echocardiography and corroborated the presence of a large ostium secundum atrial septal defect.

The surgical approach of this patient was discussed and it was excluded because of their comorbidity and was scheduled for a close follow-up for the risk of 
embolism by magnetic resonance imaging and clinical examination at the outpatient clinic.

Actually, the patient is receiving medical treatment and in the 8 months followup he is in NYHA functional class I.

\subsection{Papillary Fibroelastoma of Aortic Valve}

A 68-year-old woman with a history of pulmonary tuberculosis resolved with medical treatment two years ago and ischemic heart disease. She has a family history of dyslipidemia. The laboratory analysis showed hyperlipidemia with total cholesterol of $219 \mathrm{mg} / \mathrm{dl}, \mathrm{HDL}-31 \mathrm{mg} / \mathrm{dl}$ and LDL-145 mg/dl, Table 1 . The transthoracic echocardiogram revealed a mobile, round mass, on the right-coronary cusp of the aortic valve and the two and three-dimensional echocardiogram showed very clearly the presence of the $15 \mathrm{~mm}$ pediculated mass, highly mobile implanted in the right coronary cusp of the aortic valve, suggestive of fibroelastoma, (Figures 2(A)-(D) and Video 2).

One month later the patient had a cardioembolic stroke, probably due to highly mobile fibroelastoma and paroxysmal atrial fibrillation. Unfortunately the patients died in the two-month follow-up before surgery.
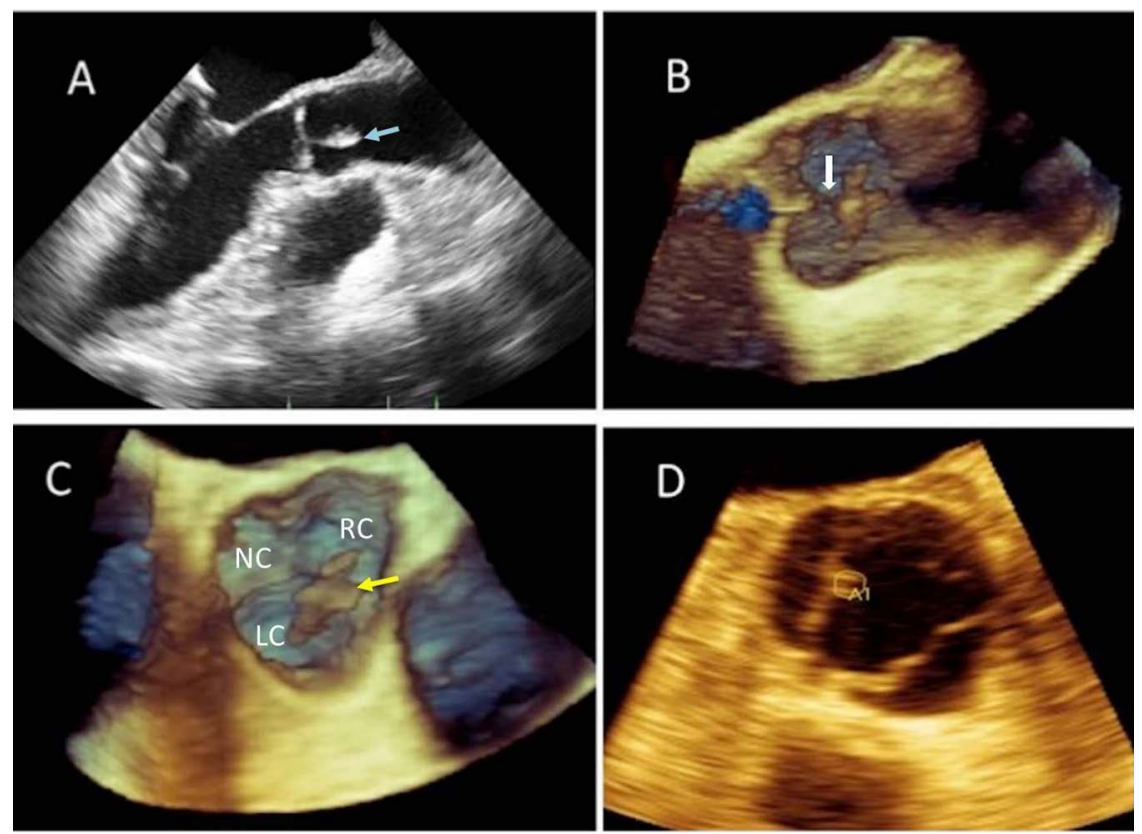

Figure 2. Transesophageal study. (A) Two-dimensional TEE in long axis shows a pediculated $15 \mathrm{~mm}$ in length (blue arrow) tumor, the pedicle joins the right coronary cusp. It has a filamentous appearance with uniform edges; (B) Image of 3D-TEE zoom of aortic valve with a sagittal cut of the valve, showing the tumor attached to the right coronary cusp by its pedicle (white arrow); (C) 3D-TEE zoom aortic valve image view from its vascular face. As we can note, there are multiple filaments associate to a valvular fibroelastoma implanted in the right coronary cusp (yellow arrow); (D) 3D-TEE off-line analysis at the level of the tumor's implantation site on the aortic valve. We can perform measurements on the pedicle of the fibroelastoma, which has an implantation area of 0.09 $\mathrm{cm}^{2}$. 


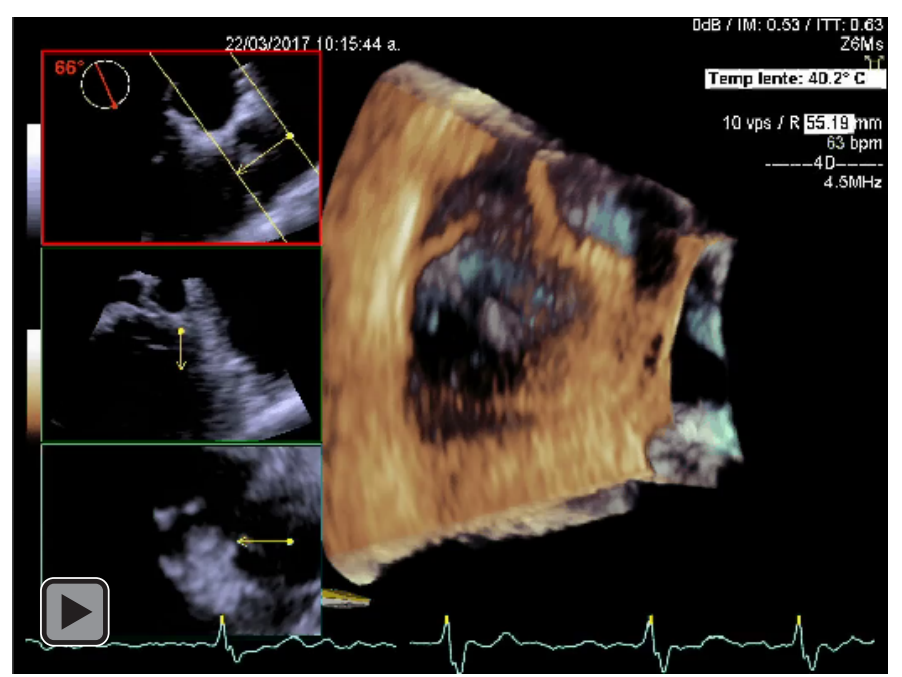

Video 2. Real-time three-dimensional mid-esophageal image, showing the aortic mass.

\section{Discussion}

Papillary fibroelastomas are benign endocardial papillomas that mainly affect the cardiac valves and account for approximately $75 \%$ of all cardiac valvular tumors [5] [6]. Our patients with fibroelastoma of the semilunary valves were asymptomatics and their diagnosis were made incidentally. The most common echocardiographic findings are echogenic and pedunculated mass or masses on the semilunary valves as we observed in our patients, especially in the case with aortic fibroelastoma, where the mass was irregular and highly mobile with size of $15 \mathrm{~mm}$. Tumor mobility has been reported to be the only independent predictor of papillary fibroelastoma related to death and nonfatal embolization [7] as occurred in our patient who developed a massive stroke and died in the follow-up, before surgery. Rarely, they may cause angina by occluding the coronary ostia. Emboli into the coronary arteries and cerebral arteries have also been described [8]. The association of pulmonary fibroelastoma with atrial septal defect has not been described before in the literature.

The differential diagnosis should be made with cardiac myxoma, Lambl excrescences, infective vegetations, and Libman Sacks endocarditis [9].

\section{Conclusions}

Papillary fibroelastoma of the semilunary valves is a rare primary cardiac benign neoplasm. The clinical presentation of cardiac papillary fibroelastoma varies from asymptomatics to severe embolic sequelae as it occurred in our patient with aortic fibroelastoma.

Echocardiography is a very important noninvasive technique for diagnosis and follow-up of these tumors. Transesophageal echocardiography allowed delineating the extent and anatomic attachment and mobility of these tumors, because its optimal high-resolution imaging. The use of 3D transesophageal echocardiography adds value in the assessment of a cardiac mass. A detailed characterization of the mass size, composition, location, mobility and relationship to 
adjacent structures enable the echocardiographer to be a new level of confidence in the diagnosis, follow-up, and surgical planning of these patients [10].

\section{Conflict of Interest}

The authors have no conflicts of interest to declare.

\section{References}

[1] Gowda, R.M., Khan, I.A., Nair, C.K., Mehta, N.J., Vasavada, B.C. and Sacchi, T.J. (2003) Cardiac Papillary Fibroelastoma: A Comprehensive Analysis of 725 Cases. American Heart Journal, 146, 404-410. https://doi.org/10.1016/S0002-8703(03)00249-7

[2] Lund, G.K., Schröder, S., Koschyk, D.H. and Nienaber, C.A. (1997) Echocardiographic Diagnosis of Papillary Fibroelastoma of the Mitral and Tricuspid Valve Apparatus. Clinical Cardiology, 20, 175-177. https://doi.org/10.1002/clc.4960200216

[3] Klarich, K.W., Enriquez-Sarano, M., Gura, G.M., Edwards, W.D., Tajik, A.J. and Seward, J.B. (1997) Papillary Fibroelastoma: Echocardiographic Characteristics for Diagnosis and Pathologic Correlation. Journal of the American College of Cardiology, 30, 784-790. https://doi.org/10.1016/S0735-1097(97)00211-8

[4] Bouhzam, N., Kurtz, B., Doguet, F., Eltchaninoff, H. and Bauer, F. (2012) Incidental Papillary Fibroelastoma Multimodal: Imaging and Surgical Decisions in 2 Patients. Texas Heart Institute Journal, 39, 731-735.

[5] Kim, E.Y., Choe, Y.H., Sung, K., Park, S.W., Kim, J.H. and Ko, Y.H. (2009) Multi-Detector CT and MR Imaging of Cardiac Tumors. Korean Journal of Radiology, 10, 164-175. https://doi.org/10.3348/kjr.2009.10.2.164

[6] Anderson, K.R., Fiddler, G.I. and Lie, J.T. (1977) Congenital Papillary Tumor of the Tricuspid Valve. An Unusual Cause of Right Ventricular Outflow Obstruction in a Neonate with Trisomy E. Mayo Clinic Proceedings, 52, 665-669.

[7] Hakim, F.A. and Aryal, M.R. (2014) Papillary Fibroelastoma of the Pulmonary Valve-A Systematic Review. Echocardiography, 31, 234-240. https://doi.org/10.1111/echo.12388

[8] Jha, N.K., Khouri, M., Murphy, D.M., Salustri, A., Khan, J.A., Saleh, M.A., et al. (2010) Papillary Fibroelastoma of the Aortic Valve-A Case Report and Literature Review. Journal of Cardiothoracic Surgery, 5, 84. https://doi.org/10.1186/1749-8090-5-84

[9] Saad, R.S., Galvis, C.O., Bshara, W., Liddicoat, J. and Dabbs, D.J. (2001) Pulmonary Valve Papillary Fibroelastoma. A Case Report and Review of the Literature. Archives of Pathology \& Laboratory Medicine, 125, 993-994.

[10] Lang, R., Badano, L., Tsang, W., Adams, D., Agricola, E., Buck, T., et al. (2012) EAE/ASE Recommendations for Image Acquisition and Display Using Three-Dimensional Echocardiography. European Heart Journal-Cardiovascular Imaging, 13, 1-46. https://doi.org/10.1093/ehjci/jer316

\section{Abbreviations}

3D-TEE: three-dimensional transesophageal echocardiography; RC: right coronary cusp; LC: left coronary cusp; NC: non-coronary cusp. 